\title{
Hydroxychloroquine in the Treatment of COVID-19: A Multicenter Randomized Controlled Study
}

\author{
Sherief Abd-Elsalam, ${ }^{1 \star}$ Eslam Saber Esmail, ${ }^{1}$ Mai Khalaf, ${ }^{1}$ Ehab Fawzy Abdo, ${ }^{2}$ Mohammed A. Medhat, ${ }^{2}$ \\ Mohamed Samir Abd El Ghafar, ${ }^{3}$ Ossama Ashraf Ahmed, ${ }_{4}^{4}$ Shaimaa Soliman, ${ }^{5}$ Ghada N. Serangawy, ${ }^{6}$ and Mohamed Alboraie ${ }^{7}$ \\ ${ }^{1}$ Department of Tropical Medicine and Infectious Diseases, Faculty of Medicine, Tanta University, Tanta, Egypt; ${ }^{2}$ Department of Gastroenterology \\ and Tropical Medicine, Faculty of Medicine, Assiut University, Assiut, Egypt; ${ }^{3}$ Department of Anesthesia, Surgical Intensive Care and Pain \\ Medicine, Faculty of Medicine, Tanta University, Tanta, Egypt; ${ }^{4}$ Department of Internal Medicine, Ain-Shams University, Cairo, Egypt; ${ }^{5}$ Public \\ Health and Community Medicine, Menoufia University, Menoufia, Egypt; ${ }^{6}$ Department of Forensic Medicine and Toxicology, Far \\ Tanta University, Tanta, Egypt; ${ }^{7}$ Department of Internal Medicine, Al-Azhar University, Cairo, Egypt
}

Abstract. The COVID-19 pandemic is showing an exponential growth, mandating an urgent ne to develo an effec ve treatment. Indeed, to date, a well-established therapy is still lacking. We aimed to evaluats safe and ffio of hydroxychloroquine (HCQ) added to standard care in patients with COVID-19. This was a ucente udomized wontrolled trial conducted at three major university hospitals in Egypt. One hundred ninety-four atte ts with nfirm diagnosis of COVID-19 were included in the study after signing informed consent. They were equally randon, red into arms: 97 patients administrated HCQ plus standard care (HCQ group) and 97 patients administer a only standaro are as a control arm (control group). The primary endpoints were recovery within 28 days, need for mecha cal ventilation, or wath. The two groups were matched for age and gender. There was no significant difference between them egarding ly of the baseline characteristics or laboratory parameters. Four patients $(4.1 \%)$ in the $\mathrm{HCQ}_{\text {group and } 5} \%$ \%) pa. nts in $\mathrm{tr}$, control group needed mechanical ventilation $(P=0.75)$. The overall mortality did not differ between the $t$ o gl "ns, as -patients $(6.2 \%)$ died in the HCQ group and $5(5.2 \%)$ died in the control group $(P=0.77)$. Univari- 10 tic $r e$ sol nalysis showed that $\mathrm{HCQ}$ treatment was not significantly associated with decreased mortality in C VID-19 patien. So, adding HCQ to standard care did not add significant benefit, did not decrease the need for yo matic an in not duce mortality rates in COVID-19 patients.

Coronaviruses are a laror amils whi may can se illness in animals or humans. In Imans severo cr onaviruses are known to cause respirator in cetrong from common cold to more severe disease such as Middle East respiratory syndrome and SARS. ${ }^{1-6}$ The 1 st recently discovered coronavirus is SARS-CoV-2 which causes COVID-19. As cases of COVID-19 continue to rise in different countries, health systems are facing enormous pressure to manage COVID-19 patients. By August 2, 2020, COVID-19 has been confirmed in about 17,660,523 million individuals worldwide and has resulted in more than 680,894 deaths. These numbers are still increasing. More than 180 countries have reported laboratoryconfirmed cases of COVID-19 on all continents, except Antarctica. ${ }^{1-4}$ In Egypt, the official number of infected patients was 94,316, with 4,834 deaths as of August 2, 2020. ${ }^{1-11}$

Although many vaccines are in development, effective therapy is needed to treat currently infected patients and prevent mortality. Chloroquine (CQ) and hydroxychloroquine (HCQ) have been used for decades in the treatment and prophylaxis of a number of conditions including malaria. The ability of these drugs to inhibit other coronaviruses, such as SARS-CoV-1, has been explored. Although generally considered safe, there are potential risks associated with taking these medications, including cardiac arrhythmia. ${ }^{7-11}$

Although an initial study in France found encouraging results for the treatment of COVID-19 with HCQ, the study was later criticized for its methodological problems, leading to skepticism about the validity of its results. Other similar results

\footnotetext{
*Address correspondence to Sherief Abd-Elsalam, Department of Tropical Medicine and Infectious Diseases, Faculty of Medicine, Tanta University, El-Giash St., Tanta 31527, Egypt. E-mail: sherif.abdelbaky@ med.tanta.edu.eg
}

were not represented in any further subsequent studies, but even reported deleterious clinical outcomes especially cardiac adverse events like prolongation of QT interval. ${ }^{8}$ On March 28 , 2020, the Food and Drug Administration (FDA) granted an emergency use authorization for use of oral formulations of $C Q$ and HCQ in the treatment of COVID-19. ${ }^{7-11}$ Based on emerging data showing $\mathrm{CQ}$ and $\mathrm{HCQ}$ as unlikely to be effective in the treatment of COVID-19, ${ }^{12,13}$ the FDA revoked its previous emergency use authorization for both drugs on June 15, 2020.

In this study, we aimed to evaluate the safety and efficacy of HCQ added to the standard of care versus the standard of care alone in patients with COVID-19.

\section{METHODS}

Patients admitted to three tertiary referral centers $(n=194)$ managing patients with suspected and confirmed COVID-19 in Egypt in the period between March and June 2020 were enrolled. The patients were clinically stratified into mild, moderate, and severe disease according to the WHO interim guidelines published on March 13, 2020. Mild cases represented patients with uncomplicated upper respiratory tract viral infection, moderate cases represented patients with pneumonia but without need for supplemental oxygen, whereas severe disease represented cases with fever or suspected respiratory infection, plus one of the following: respiratory rate $>30$ breaths $/ \mathrm{min}$, severe respiratory distress, or $\mathrm{SpO}_{2} \leq 93 \%$ on room air. ${ }^{14}$

The Egyptian Ministry of Health $(\mathrm{MOH})$ adopted a standard of care treatment protocol for COVID-19 patients. It included paracetamol, oxygen, fluids (according to assessment), empiric antibiotic (cephalosporins), oseltamivir if needed (75 mg/ 12 hours for 5 days), and invasive mechanical ventilation with hydrocortisone for severe cases if $\mathrm{PaO}_{2}<60 \mathrm{mmHg}, \mathrm{O}_{2}$ saturation $<90 \%$ despite oxygen or noninvasive ventilation, progressive hypercapnia, respiratory acidosis $(\mathrm{pH}<7.3)$, and progressive or refractory septic shock. ${ }^{15}$ 
Patients were randomized into two groups using a computerized random number generator using simple randomization with an equal allocation ratio. During randomization, the proportional allocation of each clinical stratum was equalized in both groups.

\section{Study groups.}

1. Hydroxychloroquine group: This group included 97 patients who received HCQ $400 \mathrm{mg}$ twice daily (in day 1) followed by $200 \mathrm{mg}$ tablets twice daily added to the standard of care treatment adopted by the Egyptian $\mathrm{MOH}$ for 15 days.

2. Control group: This group included 97 patients who received only the standard of care treatment adopted by the national $\mathrm{MOH}$ for 15 days.

All the patients were followed up for 4 weeks.

The study included all patients admitted with SARS-CoV-2 infection and enrolled both genders. Patient who had allergy or contraindication to $\mathrm{HCQ}$, pregnant and lactating females, and patients with cardiac problem (chronic heart failure or prolonged QT interval on electrocardiogram [ECG]) were excluded from the study.

Informed written consent was obtained from each participant, and the study was approved by the Ethics Committee of the Faculty of Medicine, Tanta University. Privacy of the participants and confidentiality of the data were assured. Risks and benefits were explained to the patients. The study was registered on clinicaltrials.gov with registration number NCT04353336.

All the participants were subjected to thorough hist y taking and full clinical examination including age, ge der, weight and height measurements, and calculation ot $\mathrm{sdy}$ mass index (BMI); medication history; and investig ,ons in form of complete blood picture, liver function te 0 , omputea tomography of the chest (CT chest), and SARS-Co -2 detection in nasopharyngeal swabs using $\mathrm{CR}$ and ECL Assessment of the studied medication side dfects as performed using a questionnaire.

Statistical analysis. Data wer alyż usin statistical Package for Social Sciences . 23 hd wt cxpressed in number, percentage (\%), me $(\bar{x})$ a tested for normality by the Shap. Wilks test. Student's $t$-test was used for normally distributea yantitative variables and Mann Whitney's test for not normalry distributed ones. Chi- square test $\left(x^{2}\right)$ was used to study association between qualitative variables, and whenever any of the expected cells were less than five, Fischer's exact test was used. Binary logistic regression was used to ascertain the effect of the potential risk factors on the patients' mortality. A two-sided $P$-value of $<0.05$ was considered statistically significant.

Post hoc power analysis. Considering the percentage of recovery as a primary endpoint and by using $\mathrm{G}^{*}$ power program, post Hoc power analysis revealed a sample power of $80.6 \%$ with the following input parameters: two-tailed $\alpha$ error $0.05,54.0 \%$ recovery rate in the $\mathrm{HCQ}$ group, $34.0 \%$ recovery in the control group, and 97 sample size in each group. ${ }^{16}$

At the time of presentatio inten ted fe $r$ was present in $44.6 \%$, continuous fever $122.3 \%$, $h$ d he in $42.9 \%$, sore throat in $25.7 \%$, anore, in $3 \%$, anosmia in $26.9 \%$, pallor in $3.4 \%$, cyanosis 4.0 , fatig in $49.0 \%$, vomiting in $13.7 \%$, diarrhea $35.0 \%$, a $61.3 \%$, and $d$, spne in $24.2 \%$ of the included patients. Oxygen saturating betweo 95 and 90 was present in $16.0 \%$, 90-85 ir $.4 \%$, and less than 85 in $6.9 \%$ of all the participants.

The omputed omography chest scans were normal in $33.1 \%$, round-gl ss opacities in $23.4 \%$, confluent opacities - $25.7 \%$, nner dation in $10.9 \%$, extensive consolidation in $3 \%$ and emphysema in only $0.6 \%$.

Th two yroups were matched for age and gender, with no sis ificant difference between them. They had no significant dift ence regarding BMI, residence, smoking, pregnant fees, or the presence of comorbidities. The patients were randomized equally between the two groups regarding the disease severity (Table 1).

There was no significant difference between the two groups regarding laboratory parameters (Table 2).

Mechanical ventilation was needed in four patients $(4.1 \%)$ in the HCQ group and $5(5.2 \%)$ in the control group, with no significant difference between the two groups $(P=0.75)$. Six patients $(6.2 \%)$ died in the HCQ group, and five patients $(5.2 \%)$ died in the control group without any significant difference between the two groups either $(P=0.76)$.

Eleven patients $(11.3 \%)$ in the HCQ group needed intensive care unit (ICU) admission, and 13 patients (13.4\%) in the

TABLE 1

Patients' characteristics between the two groups

\begin{tabular}{|c|c|c|c|c|}
\hline Character & Group $1(n=97)$ & Group $2(n=97)$ & Total $(n=175)$ & $P$-value \\
\hline Age (years), mean \pm SD & $40.35 \pm 18.65$ & $41.09 \pm 20.07$ & $40.72 \pm 19.32$ & 0.80 \\
\hline Range & $2.0-85.0$ & $2.0-83.0$ & - & - \\
\hline \multicolumn{5}{|l|}{ Gender, $n(\%)$} \\
\hline Male & $56(57.7)$ & $58(59.8)$ & $114(58.8)$ & \multirow[t]{2}{*}{0.77} \\
\hline Female & $41(42.3)$ & $39(40.2)$ & 80 (41.2) & \\
\hline \multicolumn{5}{|l|}{ Body mass index, $n(\%)$} \\
\hline Normal & $4(4.1)$ & $9(9.3)$ & $13(6.7)$ & \multirow[t]{4}{*}{0.46} \\
\hline Overweight & $32(33.0)$ & $29(29.9)$ & $61(31.4)$ & \\
\hline Obese & $40(41.2)$ & $35(36.1)$ & $75(38.7)$ & \\
\hline Morbid obesity & $21(21.6)$ & $24(24.7)$ & $45(23.2)$ & \\
\hline \multicolumn{5}{|l|}{ Residence, $n(\%)$} \\
\hline Rural & $54(55.7)$ & $46(37.4)$ & $100(51.5)$ & \multirow[t]{2}{*}{0.25} \\
\hline Urban & $43(44.3)$ & $51(52.6)$ & 94 (48.5) & \\
\hline Smoking, $n$ (\%) & $35(36.1)$ & $25(25.8)$ & $60(31.4)$ & 0.12 \\
\hline Comorbidities, $n$ (\%) & $15(15.5)$ & $12(12.4)$ & 27 (14.3) & 0.53 \\
\hline Liver diseases, $n(\%)$ & $0(0.0)$ & $2(2.1)$ & $2(1.0)$ & 0.50 \\
\hline Renal impairment, $n(\%)$ & $2(2.1)$ & $4(4.1)$ & $6(3.1)$ & 0.68 \\
\hline
\end{tabular}


TABLE 2

Laboratory parameters between the two groups

\begin{tabular}{lccc}
\hline \multicolumn{1}{c}{ Investigation } & Group 1 $(n=97)$, mean \pm SD & Group 2 $(n=97)$, mean \pm SD & $P$-value \\
\hline Hemoglobin & $13.20 \pm 2.00$ & $12.83 \pm 1.88$ & 0.19 \\
Platelets & $280.78 \pm 102.12$ & $252.08 \pm 97.03$ & 0.05 \\
White blood cells & $5.48 \pm 2.82$ & $6.07 \pm 3.376$ & 0.82 \\
Lymphocytes & $30.14 \pm 21.45$ & $31.95 \pm 17.00$ & 0.07 \\
Direct bilirubin & $0.26 \pm 0.11$ & $0.33 \pm 0.26$ & $0.58 \pm 0.26$ \\
Indirect bilirubin & $0.55 \pm 0.20$ & $3.95 \pm 0.45$ & 0.09 \\
Albumin & $4.06 \pm 0.38$ & $28.17 \pm 18.31$ & 0.07 \\
Alanine aminotransferase & $33.07 \pm 23.15$ & $26.89 \pm 179.25$ & 0.10 \\
Aspartate aminotransferase & $29.52 \pm 13.45$ & $1.06 \pm 0.15$ & 0.06 \\
International normalized ratio & $1.08 \pm 0.14$ & $28.17 \pm 220.11$ & 0.19 \\
D-dimer & $26.74 \pm 145.03$ & 0.32 & 0.42 \\
Median & 0.34 & $282.04 \pm 179.25$ & 230.0 \\
Lactate dehydrogenase & $291.52 \pm 149.47$ & $305.14 \pm 357.24$ \\
Median & 250.0 & 194.0 & 0.07 \\
Ferritin & $374.75 \pm 469.49$ & $0.98 \pm 0.27$ & 0.07 \\
Median & 234.0 & $35.86 \pm 63.60$ & 12.0 \\
Creatinine & $0.94 \pm 0.29$ & 0.05 \\
C-reactive protein & $27.88 \pm 48.91$ & 12.0 & 0.38 \\
Median & & & \\
\hline
\end{tabular}

control group needed the same $(P=0.83)$. The mean duration to negative $P C R$ was $17 \pm 3$ days in the $H C Q$ group and $18 \pm 2$ in the control group $(P=0.11)$. The $\mathrm{HCQ}$ group had a mean of $9 \pm 2$ days to show clinical improvement and $11 \pm 3$ days to hospital discharge, whereas the control group had a mean of $10 \pm 3$ to clinical improvement and $11 \pm 2$ to hospital discharge $(P=0.80$ and 0.52 , respectively) (Table 3 ).

After 28 days, there was no significant difference between the two groups regarding the clinical outcome $(P=0.07)$. Complete recovery was achieved in 52 cases $(53.6 \%)$ of the HCQ group, whereas 23 cases (23.7\%) were in mild, 8 (8.2\%) were in moderate, $8(8.2 \%)$ in severe disease status, and six patients $(6.1 \%)$ died. Among the control group, 33 patients (34.0\%) recovered completely, $39(40.2 \%)$ were in mild, 10 $(10.3 \%)$ were in moderate, 9 (9.2\%) were in severe disea status, and five patients (5.1\%) died.

By logistic regression, the overall mortality was not gnificantly associated with HCQ therapy; however, it y st nificantly related to the patient's age, alanine amip transfero serum creatinine, serum ferritin, C-reactive otein, oxyge, saturation, and the presence of diabetes p ditus (5) able 4).

Chloroquine and $\mathrm{HCQ}$ are well-, owr have been used for decades as antiparasitic ano, nti-inflammatory drugs to treat malaria and rheumato gical a orders Chloroquine was shown to be effective a ainst SARS- in invitro studies. This may be because fir aption of viral replication, changing immune syste activ an add on to its inflammatory effect. $^{17}$

The two drugs rave b on tried earlier for the treatment of SARS infectiond show promising efficacy. With the emergence SARS-CoV-2 pandemic, they have been suggested as potential eatment fo the new coronavirus 2019 based on the previous evic nce from ifferent coronavirus strains. ${ }^{18}$

$f$ nugh car xicity is a known adverse event requiring mor orim uring treatment, HCQ showed promise in treating SARS C $\sqrt{-2}$-imfected patients with multiple comorbidities clud g coronary artery disease. A large trial from India howed that $\mathrm{HCQ}$ can decrease time to recovery both in sympumatic and in asymptomatic patients with no effect on mortality. ${ }^{19}$

At the beginning of the pandemic in Europe, a small series of COVID-19 patients treated in France with HCQ showed improved decline in SARS-CoV-2 viral load compared with controls, which was augmented by the addition of azithromycin. ${ }^{7}$ However, this study had serious methodological flaws and could not be considered as a good evidence in the favor of HCQ use. ${ }^{8-11}$

Many other conflicting trials have been published in the past few months leading initially to emergency use authorization for

TABLE 3

Clinical course in both groups

\begin{tabular}{|c|c|c|c|}
\hline Clinical course & Hydroxychloroquine $(n=97)$ & Control $(n=97)$ & $P$-value \\
\hline \multicolumn{4}{|l|}{ Disease severity after 28 days, $n(\%)$} \\
\hline Recovered & $52(53.6)$ & $33(34.0)$ & 0.06 \\
\hline Mild & $23(23.7)$ & $39(40.2)$ & \\
\hline Moderate & $8(8.2)$ & $11(11.3)$ & \\
\hline Severe & $8(8.2)$ & $9(9.2)$ & \\
\hline Death & $6(6.1)$ & $5(5.1)$ & \\
\hline Need for ICU & $11(11.3)$ & $13(13.4)$ & 0.83 \\
\hline Duration to negative $\mathrm{PCR}$, mean $\pm \mathrm{SD}$ & $17.01 \pm 2.98$ & $17.64 \pm 2.45$ & 0.11 \\
\hline Duration to clinical improvement, mean \pm SD & $9.43 \pm 1.87$ & $9.52 \pm 2.94$ & 0.80 \\
\hline Duration to hospital discharge, mean \pm SD & $11.04 \pm 2.71$ & $11.27 \pm 2.19$ & 0.52 \\
\hline
\end{tabular}


TABLE 4

Univariate regression of the potential risk factor of mortality

\begin{tabular}{|c|c|c|c|c|}
\hline \multirow[b]{3}{*}{ Variable } & \multicolumn{4}{|c|}{ Univariate } \\
\hline & \multirow[b]{2}{*}{$P$-value } & \multirow[b]{2}{*}{ OR } & \multicolumn{2}{|c|}{$95 \% \mathrm{Cl}$} \\
\hline & & & Lower & Upper \\
\hline Age & $<0.001$ & 1.081 & 1.035 & 1.129 \\
\hline Gender & 0.736 & 1.243 & 0.351 & 4.396 \\
\hline Smoking & 0.997 & - & - & - \\
\hline Alanine aminotransferase & $<0.001$ & 1.047 & 1.024 & 1.071 \\
\hline Albumin & 0.025 & 0.201 & 0.050 & 0.816 \\
\hline Creatinine & $<0.001$ & 47.506 & 7.347 & 307.17 \\
\hline Ferritin & 0.002 & 1.002 & 1.001 & 1.003 \\
\hline C-reactive protein & $<0.001$ & 1.029 & 1017 & 1.040 \\
\hline $\mathrm{O}_{2}$ saturation & $<0.001$ & & & \\
\hline $95-90$ & 0.035 & 13.739 & & 157.62 \\
\hline 85-90 & $<0.001$ & 632.00 & & $7,725.0$ \\
\hline $\mathrm{DM}$ & 0.001 & 9.293 & & 33.792 \\
\hline Hydroxychloroquine treatment & 0.757 & 0.824 & & 2.797 \\
\hline
\end{tabular}

HCQ use in the treatment of COVID-19 and later on withdrawal of this authorization by the FDA. Initial observational trials of $\mathrm{HCQ}$ use in hospitalized patients showed that there were no increased risks of mortality or intubation in groups receiving $\mathrm{HCQ}$ or the control group who received only standard of care although patients who received $\mathrm{HCQ}$ were more critically ill. ${ }^{20}$ However, many published trials had some methodological flaws and missed important patient outcomes urging the ner for properly designed, adequately powered trials to sur fort clinical decisions of HCQ use in treating COVID-19 patien 21

Administration of HCQ did not result in a significe cly high probability of conversion from positive to negat $\mathrm{A}$ ' $\mathrm{R}$ than standard care alone in patients admitted to hosph with nonresponsive mild-to-moderate COVID $g$ in China. $\mathrm{d}$ verse events were more frequent in $\mathrm{H}^{\prime} Q$ reci ents than in non-recipients. ${ }^{22}$

A meta-analysis included seven tes halar number of patients showing that treatm it wit $\mathrm{HCQ}$, associated with faster improvement of fer co r less radiological progression of lung lesions. How r, there was no difference in the virological cure, clinical impro ement, or mortality. ${ }^{23}$

Many subsequent trials did not show benefit for HCQ use in COVID-19, with some of them suggesting more adverse events associated with its use. ${ }^{22-24}$ A recent clinical trial by Skipper et al. ${ }^{12}$ studied the change in symptom severity over 14 days in nonhospitalized patients between HCQ and control groups and did not find any significant difference $(P=0.12)$. Another trial by Cavalcanti et al. ${ }^{13}$ compared three groups; standard care group, standard care plus $\mathrm{HCQ}$, and standard care plus HCQ and azithromycin. The clinical status at 15 days assessed by a seven-level ordinal scale did not show any significant difference among the three groups. Moreover, elevated liver enzymes and prolonged QT intervals were more frequent among patients who used $\mathrm{HCQ}$.

In our study, adding $\mathrm{HCQ}$ to standard care did not add an extra benefit for the patients. Hydroxychloroquine arm was similar in all outcomes. Moreover, HCQ was not effective as postexposure prophylaxis against COVID-19 when administered within 4 days after exposure. ${ }^{25-29}$

Limitations of the study include small sample size which was not adequately powered for survival endpoint. The number of the included patients was limited because in Egypt, tertiary carn hospitals vere assigned lately to deal with COVID-1 patients and hau many regulations by the Egyptian $\mathrm{MOH} .7$ e study it ks long-term follow-up which could be address in a pro pective trial. The utility of HCQ should be aluated maro multicenter trials either alone or in combition the drugs/lines of treatment. The role of HCQ as a or nylanis against SARS-CoV-2 infection should be am ing the future trials also.

In onclusion, our trial adds extra evidence from Egypt that 2 may not be beneficial as a treatment for COVID-19.

Received July 17, 2020. Accepted for publication August 7, 2020.

Published online August 14, 2020.

Acknowledgment: Publication charges for this article were waived due to the ongoing pandemic of COVID-19.

Authors' addresses: Sherief Abd-Elsalam, Eslam Saber Esmail, and Mai Khalaf, Department of Tropical Medicine and Infectious Diseases, Faculty of Medicine, Tanta University, Tanta, Egypt, E-mails: sherif.abdelbaky@med.tanta.edu.eg, eslam.esmail@med.tanta.edu.eg, and mai.a.khalaf@med.tanta. Ehab Fawzy Abdo and Mohammed A. Medhat, Department of Tropical Medicine and Gastroenterology, Faculty of Medicine, Assiut University, Assiut, Egypt, E-mails: ehab_ mostafa99@yahoo.com and mmedhat83@gmail.com. Mohamed Samir Abd El Ghafar, Department of Anesthesia, Surgical Intensive Care and Pain Medicine, Faculty of Medicine, Tanta University, Tanta, Egypt, E-mail: mohamed.abdelghafar1@med.tanta.edu.eg. Ossama Ashraf Ahmed, Department of Internal Medicine, Ain-Shams University, Cairo, Egypt, E-mail: ossamaashraf@yahoo.com. Shaimaa Soliman, Public health and Community Medicine, Menoufia University, Menoufia, Egypt, E-mail: shaimaasherif@hotmail.com. Ghada N. Serangawy, Department of Forensic Medicine and Toxicology, Faculty of Medicine, Tanta University, Tanta, Egypt, E-mail: elashryheba@yahoo.com. Mohamed Alboraie, Department of Internal Medicine, Al-Azhar University, Cairo, Egypt, E-mail: alboraie@azhar.edu.eg.

This is an open-access article distributed under the terms of the Creative Commons Attribution (CC-BY) License, which permits unrestricted use, distribution, and reproduction in any medium, provided the original author and source are credited.

\section{REFERENCES}

1. Zhu N et al.; China Novel Coronavirus Investigating and Research Team, 2020. A novel coronavirus from patients with pneumonia in China, 2019. N Engl J Med 382: 727-733.

2. Yin Y, Wunderink RG, 2018. MERS, SARS and other coronaviruses as causes of pneumonia. Respirology 23: 130-137. 
3. Zhou P et al., 2020. A pneumonia outbreak associated with a new coronavirus of probable bat origin. Nature 579: 270273.

4. Bhatnagar T, Murhekar MV, Soneja M, Gupta N, Giri S, Wig N, Gangakhedkar R, 2020. Lopinavir/ritonavir combination therapy amongst symptomatic coronavirus disease 2019 patients in India: protocol for restricted public health emergency use. Indian J Med Res 151: 184-189.

5. Lim J, Jeon S, Shin HY, Kim MJ, Seong YM, Lee WJ, Choe KW, Kang YM, Lee B, Park SJ, 2020. Case of the index patient who caused tertiary transmission of COVID-19 infection in Korea: the application of lopinavir/ritonavir for the treatment of COVID19 infected pneumonia monitored by quantitative RT-PCR. J Korean Med Sci 35: e79.

6. Cao B, 2020. A trial of lopinavir-ritonavir in adults hospitalized with severe COVID-19. N Engl J Med 382: 1787-1799.

7. Gautret $P$ et al., 2020. Hydroxychloroquine and azithromycin as a treatment of COVID-19: results of an open-label nonrandomized clinical trial. Int J Antimicrob Agents 56: 105949.

8. Molina JM, Delaugerre C, Goff JL, Mela-Lima B, Ponscarme D Goldwirt L, de Castro N, 2020. No evidence of rapid antiy clearance or clinical benefit with the combination of hyd sxychloroquine and azithromycin in patients with severe CC D-19 infection. Med Mal Infect 50: 384.

9. Gnegel G, Hauk C, Neci R, Mutombo G, Nyaah F Nistuba Häfele-Abah C, Heide L, 2020. Identification ified chlo roquine tablets in Africa at the time of the COMD-19, ndemic. Am J Trop Med Hyg 103: 73-76.

10. Xie $\mathrm{M}$, Chen Q, 2020. Insight into 2019 ovel coronavirus an updated interim review and lesse from ARS-CoV and MERS-CoV. Int J Infect Dis 94: 119-

11. Abena PM et al., 2020. Chloroqu and h, roxych loquine for the prevention or treatment $\mathrm{CO}$ D-19, $4 \mathrm{fr}$ a: caution for inappropriate off-label us in heal, care setwings. Am J Trop Med Hyg 102: 1184-1188

12. Skipper CP et al., 2020. Hydro, hloroquine in nonhospitalized adults with early COVID-19: a râ. 'omized trial. Ann Intern Med M20-M4207.

13. Cavalcanti $A B$ et al.; Coalition COVID-19 Brazil I Investigators, 2020. Hydroxychloroquine with or without azithromycin in mildto-moderate COVID-19. N Engl J Med. Available at: https:// doi.org/10.1056/NEJMoa2019014.

14. World Health Organization, 2020. Clinical Management of Severe Acute Respiratory Infection (SARI) When COVID-19 Disease Is Suspected Interim Guidance. Available at: https://apps.who.int/ iris/bitstream/handle/10665/331446/WHO-2019-nCoV-clinical2020.4-eng.pdf?sequence=1\&isAllowed=y. Accessed March 13, 2020.

15. Egyptian Ministry of Health and Population (MOH), 2020. Diagnosis and Treatment Protocol for COVID-19. Available at: http://www.mohp.gov.eg/QuickServiceDetails.aspx?subject_ id=3686. Accessed March 24, 2020.
16. Faul F, Erdfelder E, Lang AG, Buncher A, 2007. G*Power 3: a flexible statistical power analysi havioral, and biomedical scir ces. Ben Res Methods 39: 175-191.

17. Principi N, Esposito S, 2029 Chlo quine or droxychloroquine for prophylaxis of CO -19 . Lan Inf $i$ Dis. doi: 10.1016/ S1473-3099(20)30?

18. Udwadia ZF, Malu R a D, Joshi SR, 2020. Hydroxychloroquine fo COVIL s: what our current state of knowledge? J Asc Physician 'ndi o8: 48-52.

19. Bhandaris al., '20. Chara dristics, treatment outcomes and role of hydroxych roquine among 522 COVID-19 hospitalized pati in Jaipur a: an epidemio-clinical study. J Assoc $P$ sicians India 68: 1J-19.

20. Ge is J et al., 20. Observational study of hydroxychloroquine in hospitalize patients with COVID-19. $N$ Engl J Med 382: $24 .-2418$.

- Alexana , Debono VB, Mammen MJ, lorio A, Aryal K, Deng D, card E, Alhazzani W, 2020. COVID-19 coronavirus research as o wrall low methodological quality thus far: case in point for chloroquine/hydroxychloroquine. J Clin Epidemiol 123: 120126.

22. ang $W$ et al., 2020. Hydroxychloroquine in patients with mainly mild to moderate coronavirus disease 2019: open label, randomised controlled trial. BMJ 369: $\mathrm{m} 1849$.

23. Sarma $P$ et al., 2020. Virological and clinical cure in COVID-19 patients treated with hydroxychloroquine: a systematic review and meta-analysis. J Med Virol 92: 776-785.

24. Horby P et al., 2020. Effect of hydroxychloroquine in hospitalized patients with COVID-19: preliminary results from a multi-centre, randomized, controlled trial. medRxiv. Available at: https://doi.org/10.1101/ 2020.07.15.20151852.

25. Boulware DR et al., 2020. A randomized trial of hydroxychloroquine as postexposure prophylaxis for COVID-19. N Engl J Med 383: 517-525.

26. Khan MS, Butler J, 2020. Hydroxychloroquine as postexposure prophylaxis for COVID-19. $N$ Engl $J$ Med 383. Available at: https://doi.org/10.1056/NEJMc2023617.

27. Mohamed AA, Mohamed N, Mohamoud S, Zahran FE, Khattab RA, El-Damasy DA, Alsayed E, Abd-Elsalam S, 2020. SARSCoV-2: the path of prevention and control. Infect Disord Drug Targets. Available at: https://doi.org/10.2174/187152652066 6200520112848.

28. Sarin SK et al.; APASL COVID Task Force, APASL COVID Liver Injury Spectrum Study, 2020. Pre-existing liver disease is associated with poor outcome in patients with SARS CoV2 infection; the APCOLIS Study (APASL COVID-19 Liver Injury Spectrum Study). Hepatol Int 1-11.

29. Abd-Elsalam S, Elkadeem M, Glal KA, 2020. Chloroquine as chemoprophylaxis for COVID-19: will this work? Infect Disord Drug Targets. Available at: https://doi.org/10.2174/1871526520 666200726224802. 